\title{
Medos em primigestas para o parto
}

\author{
Fears in primiparous women at the time of delivery
}

Miedos en primíparas por el parto

\begin{abstract}
Murilo Venancio Gaiowski ${ }^{1 *}$, Ana Luiza Bresser Vilas Boas Furini ${ }^{1}$, Milena Torres Guilhem Lago ${ }^{1}$, Fabiana Fontana Medeiros ${ }^{2}$, Adriana Bragantine ${ }^{1}$.
\end{abstract}

\section{RESUMO}

Objetivo: Desvelar os medos em primigestas para o momento do parto. Métodos: Estudo qualitativo, realizado através de entrevistas com 21 gestantes. A primeira etapa teve o intuito de coletar os medos apresentados para o momento do parto; já a segunda etapa teve como justificativa, desvelar os medos apresentados no pré-natal. Foram utilizados os procedimentos de análise de conteúdo de Bardin. Resultados: Após análise de conteúdo emergiram cinco categorias: "Desvelando os motivos para o medo do parto vaginal; Vivenciando o desconhecido fenômeno para o parto; Revelando o medo de escassez nos recursos humanos e tecnológicos; Medo da influência do parto no desfecho neonatal e Revelando as desmistificações ao medo do parto". Conclusão: As gestantes no pré-natal apontaram medos relacionados às suas inseguranças, medo do desconhecido, sobre a preparação profissional, relacionado a experiências alheias e de violência obstétrica, entretanto após passarem pelo momento do parto, alguns medos foram confirmados e outros não.

Palavras-chave: Cuidado pré-natal, Gestantes, Medo, Parto, Enfermagem materno-Infantil.

\begin{abstract}
Objective: To unveil fears in primiparous women at the time of delivery. Methods: Qualitative study, conducted through interviews with 21 pregnant women. The first stage was intended to collect the fears presented for the moment of delivery; the second stage was justified, unveiling the fears presented during prenatal care. Bardin's content analysis procedures were used. Results: After content analysis, five categories emerged: "Unveiling the reasons for fear of vaginal delivery; Experiencing the unknown phenomenon for childbirth; Revealing the fear of scarcity in human and technological resources; Fear of the influence of childbirth on the neonatal outcome and Revealing demystifications to fear of childbirth". Conclusion: The prenatal pregnant women pointed out fears related to their insecurities, fear of the unknown, about professional preparation, related to other people's experiences and obstetric violence, however after going through the moment of delivery, some fears were confirmed and others were not.
\end{abstract}

Keywords: Prenatal care, Pregnant women, Fear, Parturition, Maternal-childnursing.

\section{RESUMEN}

Objetivo: Desvelar miedos en primíparas al momento del parto. Métodos: Estudio cualitativo, realizado mediante entrevistas a 21 gestantes. La primera etapa estaba destinada a recoger los miedos presentados para el momento del parto; la segunda etapa fue justificada, desvelando los miedos presentados durante la atención prenatal. Se utilizaron los procedimientos de análisis de contenido de Bardin. Resultados: Después del análisis de contenido, surgieron cinco categorías: "Revelando las razones del miedo al parto vaginal; Experimentar el fenómeno desconocido del parto; Revelando el miedo a la escasez de recursos humanos y tecnológicos; Miedo a la influencia del parto en el resultado neonatal y desmitificaciones reveladoras del miedo al parto". Conclusión: Las gestantes prenatales señalaron miedos relacionados con sus inseguridades, miedo a lo desconocido, sobre la preparación profesional, relacionados con las vivencias ajenas y la violencia obstétrica, sin embargo luego de pasar por el momento del parto se confirmaron algunos miedos y otros no.

Palabras clave: Atención prenatal, Mujeres embarazadas, Miedo, Parto, Enfermería maternoinfantil.

${ }^{1}$ Centro Universitário Filadélfia (UniFil), Londrina - PR. *E-mail: muri_lo_venancio@hotmail.com

2 Universidade Estadual de Londrina (UEL), Londrina - PR. 


\section{INTRODUÇÃO}

Atualmente, diversos aspectos emocionais da gravidez, parto e puerpério são reconhecidos como períodos de intensas transformações psíquicas, existenciais e hormonais, sendo aumentados seus níveis, deixando as mulheres vulneráveis neste momento (FREGONESE AA, 2014; ZANATTA E, et al., 2017).

Essas transformações acompanham diversos questionamentos e inseguranças para as gestantes, principalmente para primigestas que irão passar por esse momento pela primeira vez, destacando-se o parto vaginal, medo da dor, ideias de lesões fisiológicas e anatômicas e riscos para o feto (TOSTES NA e SEIDL EMF, 2016; KOTTWITZ F, et al., 2017).

É notório, o medo das consequências do parto, como as altas taxas de mortalidade materno-infantil, longo período de recuperação, em caso de parto cesárea, falta de atendimento às suas necessidades no momento do parto por parte da equipe médica, dentre outras (REIS TLR, et al., 2017).

As expectativas geradas afetam a visão da experiência do seu parto e pós-parto, principalmente se as informações obtidas por ela forem ineficazes, pois a maioria dos medos e inseguranças se dão pelo desconhecido (ZANATTA E, et al., 2017).

Nesse ponto, a assistência para a gestante é de extrema importância, tanto de familiares, como da equipe profissional, todos possuem papel fundamental para que o momento do parto seja feito de maneira mais confortável possível, podendo contribuir consideravelmente para que muitos dos medos e inseguranças da gestante sejam desmistificados e superados por ela (BRASIL, 2017; LONDRINA, 2016).

A vivência do parto é inédita para cada mulher, o que leva a necessidade de um atendimento diferenciado, exclusivo e individual, por parte do hospital ou maternidade. Dessa maneira, a particularidade de cada situação pode ser suprida por parte dos profissionais de saúde, tornando o momento satisfatório para a gestante, a qual será protagonista de seu parto (BRASIL, 2014; VALADAO CL e PEGORARO RF, 2020).

Por isso deve-se ressaltar que o acompanhamento, a escuta e orientações adequadas diminuem possíveis sentimentos negativos, tabus e preconceitos que envolvem a gestação. É neste momento que o enfermeiro terá seu papel de importância realizando um pré-natal de qualidade, criando um vínculo especial que será duradouro para que esta mulher se sinta à vontade para tirar dúvidas, gerando confiança para o momento do seu parto (NUNES GS, et al., 2018; WESCHENFELDER DT, et al., 2019). Contudo, a questão norteadora desse trabalho foi: quais são os medos em primigestas para a hora do parto? Tendo como principal objetivo desvelar os medos em primigestas para o momento do parto.

\section{MÉTODOS}

Trata-se de um estudo qualitativo, descritivo e exploratório, realizado através de entrevistas com gestantes. A pesquisa foi realizada em uma unidade básica de saúde (UBS) de uma cidade localizada na região dos Campos Gerais do estado do Paraná. Os serviços da rede pública de saúde foram escolhidos por atender a maior parte das gestantes do município.

A coleta da primeira etapa teve por intuito a identificação dos medos das primigestas para a hora do parto sendo realizada durante a consulta de pré-natal, com início em julho de 2019 findando-se em agosto de 2019. Já a segunda etapa foi realizada pela busca ativa através de contato telefônico para que as mulheres participantes da primeira etapa comparecerem à consulta puerperal, no alcance de desvelar os medos apontados por elas na primeira etapa, que teve início em dezembro de 2019 sendo encerrada por completo em janeiro de 2020.

Foram utilizados como critérios de inclusão: mulheres que gestam pela primeira vez (primigesta), não ter histórico de abortamento anterior; ter, no mínimo, 10 semanas de gestação; fazer acompanhamento para gestação de risco habitual, médio e alto risco e fazer acompanhamento pré-natal pelo Sistema Único de Saúde (SUS).

Foram critérios de exclusão: primigestas com transtorno mental; malformação fetal; portadoras de infecções sexualmente transmissíveis (IST's); ter doenças ou complicações graves de saúde; e gestantes adolescentes sem assinatura do responsável. 
Participaram do estudo 31 gestantes, sendo dessas selecionadas apenas 21 que prosseguiram na pesquisa, mesmo após contato telefônico as 11 gestantes restantes não compareceram para a consulta puerperal agendada, sendo assim, excluídas automaticamente deste estudo.

As consultas de pré-natal do município não são realizadas por equipe multiprofissional (médico obstetra, enfermeiro e dentista) como preconizada pelo Ministério da Saúde (2012), e sim apenas pelo médico de plantão e dentista.

As coletas de dados de ambas as etapas foram realizadas em uma sala disponibilizada pela unidade básica de saúde conduzidas pelo próprio pesquisador, utilizando-se de alguns métodos: diário de campo para anotações durante a coleta, gravador e os instrumentos da pesquisa.

Para a integridade da pesquisa foi realizado um teste piloto para melhor adequação dos instrumentos utilizados. Esses instrumentos foram desenvolvidos em dois formulários para entrevista semiestruturada junto ao Núcleo de Estatística e Diagnóstico (NED) do Centro Universitário Filadélfia (UniFil), para serem coletados na primeira etapa no momento da consulta de pré-natal com questões de cunho, questões referentes à gestação e também questões abertas sobre medos e expectativas para o momento do parto.

O segundo formulário foi desenvolvido para ser realizado na segunda etapa no momento da consulta puerperal com questões sobre o momento do parto e questões abertas sobre os medos superados e não superados nesse momento, se teria uma nova gestação baseada no primeiro parto, e por último sobre a satisfação e qualidade dos profissionais de saúde presentes no momento do parto.

Por fim resultaram-se as seguintes perguntas norteadoras: Quais são seus medos para a hora do parto?; Quais medos foram desvelados após o momento do parto?

A pesquisa teve em ambas as etapas a duração de 15 minutos, sendo gravadas e transcritas na íntegra. Foi utilizada a correção do português sem alterar os sentidos das falas e os nomes das participantes foram codificados.

Para a obtenção dos resultados, optou-se por utilizar os procedimentos de análise de conteúdo, segundo Bardin $L$ (2016), que envolveu a primeiro momento, a leitura flutuante das entrevistas para definir palavraschaves e, em um segundo momento, a leitura horizontal das mesmas, que teve a intenção de identificar as categorias.

A pesquisa foi conduzida de acordo com os padrões éticos exigidos (Resoluções 466/2012 - 510/2016 580/2018, do Ministério da Saúde), sendo aprovado pelo Comitê de Ética em Pesquisa com Seres Humanos da UniFil (CEP/UniFil) com CAAE: 14965319.8.0000.5217 no dia 06 de julho de 2019.

\section{RESULTADOS}

As entrevistadas eram, em sua maioria, jovens: a média de idade foi de 22 anos, variando de 15 a 38 anos. As mesmas possuíam diferentes idades gestacionais, com média 26,2 semanas, variando de 10 a 39 semanas. Quinze gestantes eram casadas e seis se declararam solteiras. Em relação à religião, a maioria das gestantes eram evangélicas, totalizando treze gestantes, seguido por sete que eram católicas e uma sem religião.

Quanto à escolaridade, onze gestantes das quais foram maioria tinham o ensino médio completo, seguido por quatro que apresentavam ter ensino fundamental II, três o ensino superior, duas o ensino fundamental I e uma havia feito pós-graduação. Nota-se, portanto, que quinze participantes tinham nível de escolaridade elevado.

Ao serem questionadas sobre o planejamento da gravidez, a maioria relatou que o casal não planejou a gravidez com o total de onze gestantes, sendo assim, as outras dez planejaram sua gestação. Foram questionadas também sobre qual tipo de parto que pretendiam realizar, dezoito delas tinham desejo pelo parto vaginal e apenas três referiram preferência pelo parto cesárea. Por fim, a resolução dos partos não seguiu conforme a preferência da maioria, totalizando apenas nove partos vaginais e tendo como maioria doze partos cesárea. 


\section{Desvelando os motivos para o medo do parto vaginal}

A primeira categoria "desvelando os motivos para o medo do parto vaginal", revelou-se diversas justificativas para o medo do parto, como casos de violência obstétrica, realização do toque vaginal e o medo da queda do bebê durante o nascimento. Os medos trazidos sobre o momento do parto foram justificados por relatos da vivência de outras pessoas, os quais foram preponderantes para o medo das mulheres.

"Casos de violência obstétrica que a gente escuta muito falar, algumas coisas que possam deixar a gente constrangido, as posições do parto [...]”. (Entrevistada 1)

"[...]tenho medo dos toques de qualquer jeito do médico". (Entrevistada 2)

"Na hora de tirar a criança já aconteceu do médico tirar a criança e derrubar como uma amiga minha falou [...]". (Entrevistada 3)

\section{Vivenciando o desconhecido fenômeno para o parto}

A segunda categoria "vivenciando o desconhecido fenômeno para o parto", desvelou-se por meio dos sentimentos de não conhecer a intensidade da dor, assim como não saber como se dará o comportamento da própria mulher diante da dor desconhecida. O medo do desconhecido fenômeno parto gerou sentimentos de incertezas para o momento do parto, onde a mulher tem medo de não conseguir atingir o desfecho final que é a realização do parto.

"A dor, a gente não sabe também como vai ser, a gente planeja uma coisa aí chega lá vai que é diferente né, vai que acontece alguma coisa, você fica pensando em tudo, acho que é mais assim o que eu vou sentir na hora, a dor, o desespero se eu vou tá calma na hora (rs) [...]". (Entrevistada 4)

"Meu único medo é de ter dificuldade, de eu não conseguir ganhar meu bebê de parto normal". (Entrevistada 5)

"Eu quero normal, e meu medo é não conseguir ganhar normal e aí ter que ir para uma cesárea de emergência [...]". (Entrevistada 6)

\section{Revelando o medo de escassez nos recursos humanos e tecnológicos}

A terceira categoria "revelando o medo de escassez nos recursos humanos e tecnológicos", revelouse nos receios de não saber se haverá e qual o profissional prestará o atendimento para o suprimento das necessidades na realização do parto, assim como a infraestrutura hospitalar suficiente para a realização do parto.

O desconhecimento do profissional capacitado que conduzirá o parto, e a incerteza do suprimento de recursos tecnológicos hospitalar, gerou sentimentos de preocupação quanto ao recebimento da qualidade assistencial, assim como a possibilidade de desfecho negativo para o parto.

"[...] chegar no hospital e ter que fazer de emergência e não ter o médico na emergência, não saber quem vai estar lá e me tratar mal [...]". (Entrevistada 6)

‘[...] tem que ter alguém preparado lá de profissional, vai que no meu momento não tenha alguém preparado". (Entrevistada 4)

"Na hora do parto tenho muito medo de dar algo errado, faltar recursos no hospital". (Entrevistada 1)

\section{Medo da influência do parto no desfecho neonatal}

A quarta categoria "Medo da influência do parto no desfecho neonatal" desvelou-se quanto a possibilidade de intercorrências negativas ao recém-nascido causadas pelo mal desfecho do parto, revelado por meio da capacidade materna ao enfrentamento da dor, trabalho de parto prolongado. 
"Tenho medo de não aguentar sabe? A dor de não chegar a sair, de prejudicar minha filha, entendeu?". (Entrevistada 7)

"Medo de dar algo errado com o bebê, de passar da hora, dele não respirar direito hora que nascer, nascer e ir para incubadora, é mais isso mesmo de dar algo errado com ele [...]". (Entrevistada 8)

\section{Revelando as desmistificações ao medo do parto}

No que tange a quinta categoria "Revelando as desmistificações ao medo do parto", revelou-se que após a mulher ter vivenciado a experiência do parto, foram desmistificados os medos referentes à escassez de recursos humanos e para a possibilidade da saída do bebê pelo canal vaginal. Para o alcance de tais revelações justificou-se a presença do profissional enfermeiro para realização de diagnóstico obstétrico e intervenção com o médico obstetra.

A possibilidade da saída do bebê pela via vaginal, desmistificou o medo de intercorrências durante a passagem no canal de parto, a experiência vivenciada do parto vaginal foi determinante para as desmistificações do medo do parto.

"Tinha medo de não ter alguém preparado para me atender, mas a enfermeira que viu que o meu filho tinha feito cocô e já ligou pro médico, que me transferiu pra Campo Largo". (Entrevistada 4)

"Só o medo da anestesia que sente, depois não sente mais...achei que ia sentir o corte, a agulha e vi que não sente dor, só a anestesia mesmo". (Entrevistada 9)

"[...] tinha medo que a criança entalasse, mas não entalou e não precisava eu ter esse medo". (Entrevistada 3)

Entretanto, para algumas mulheres não foi possível a desmistificação das expectativas sobre o parto vaginal, evidenciado por meio da não evolução para o parto normal, despreparo técnico à passagem de cateter vesical de urina, rispidez médica, a realização de vários toques vaginais, violência obstétrica, e omissão de informações dadas pela equipe profissional.

"Eu tinha medo de não evoluir para parto normal, e foi o que realmente aconteceu, porém, minha família super me ajudou, mesmo sendo de longe". (Entrevistada 10)

"Tinha medo de algum tipo de violência. A menina não conseguia passar a sonda e me machucou, não me explicaram nada dos procedimentos, o médico foi super estúpido, e a enfermeira que contratei não pôde entrar[...]". (Entrevistada 1)

"Os toques que lembro ter dito que morria de medo, o médico ficou me tocando toda hora". (Entrevistada 2)

"Eu cheguei lá no hospital em trabalho de parto mas eu não sabia que eu estava em trabalho de parto, a enfermeira pegou e me examinou e falou "olha, sua neném já está nascendo, se fazer força já nasce", aí eu já tomei um choque, mas eu já estava com muita dor aí as enfermeira me levaram para a sala de parto, mas eu não aguentava com a dor e eu gritava mesmo né, e de repente chegou o médico assim e as enfermeiras todas me acalmando, mas ele mandou eu calar a boca, mas não dava, era muita dor, aí ele pegou e deu um tapa na minha cara, para eu calar a boca, do nada, eu lembro que eu gritei de novo, eu não fiz nada e ninguém também fez nada, aí depois subiram em cima da minha barriga, empurraram, o neném nasceu e pronto, depois fui para o quarto, demorou um pouco a enfermeira trouxe o neném, ela falou para eu descansar um pouco, o médico passou lá no dia seguinte e eu nem quis olhar na cara dele, não fiquei satisfeita porque ninguém fez nada, ninguém fez nada. Nunca mais quero engravidar, por causa de toda a violência que eu sofri". (Entrevistada 6) 
"Ah, não foi muito assim de acordo não, primeiro em relação ao parto né? Eu queria uma coisa aí não teve nenhum problema e o doutor resolveu cesárea, ninguém me falou nada do motivo [...]”. (Entrevistada 11)

"Mais ou menos, o médico deveria me explicar mais as coisas do meu parto [...]". (Entrevistada 9)

"Sim, foram legais, só que ninguém me explicou nada o que estava acontecendo, nem durante e nem depois do parto [...]". (Entrevistada 12)

\section{DISCUSSÃO}

Na maioria das gestantes foi observado que o medo do desconhecido gera incertezas e questionamentos devido à vulnerabilidade no momento do parto. Em estudo apresentado aponta que a vulnerabilidade da mulher se dá pela própria gestação devido aos elevados níveis de hormônio, juntamente com o desconhecido a respeito dos procedimentos necessários e as formas dos quais são realizados, fazem da mulher uma vítima em potencial, pois neste momento está propicia a confiar nas condutas dos profissionais sem questionamentos, por este motivo a insegurança e o medo entram em pauta (SANTOS ACC, 2019).

Evidencia-se também que muitos dos medos apresentados, como por exemplo, o toque vaginal de rotina e a violência obstétrica, foram fatores de destaque. A intervenção do toque sem evidências de qualidade, não devem ser disseminadas devido à sensibilidade das mulheres no momento deste procedimento, acarretando em constrangimento e dor (DOWNE S, et al., 2013).

Dentre os procedimentos invasivos ocorreu ainda a omissão de informações, o que gera instabilidade, impedindo que a mulher se torne a principal protagonista de seu parto por não the darem a oportunidade de escolha.

É de direito de toda mulher, ter o direito de escolha, ser informada de todo procedimento e ter explicação clara sobre riscos e benefícios em relação a sua saúde e a do seu bebê. Por tanto o plano de parto é um documento que entra como forma de guiar os profissionais de saúde a respeito do que a mulher espera e deseja de seu parto, o plano de parto deve ser respeitado pelos profissionais e instituições de saúde (ZORZAM B e CAVALCANTI P, 2017).

A violência obstétrica teve visibilidade relevante neste trabalho, sendo bastante citado pelas gestantes na primeira etapa, dentro da categoria "Revelando as desmistificações ao medo do parto", mostrou-se como realidade e infelizmente não foi desmistificado.

Diante da Lei oㅜ 17.097, de 17 de janeiro de 2017, do estado de Santa Catarina, que aborda a implantação de medidas de proteção às gestantes e parturientes, discorre como violência obstétrica: ofensa verbal ou física; tratamento de forma agressiva, não empática ou zombeteira; recriminar a mulher por gritar, chorar, ter medo ou algo relacionado ao seu corpo como estrias, obesidade ou evacuações; inferiorizar a mulher não lhe dando atenção as dúvidas ou dando-lhe nomes que a infantilize; levar a mulher para cesárea sem necessidade, fazendo-a acreditar ser necessário; negar acompanhante da preferência da mulher e deixá-la sem comunicação; fazer procedimentos dolorosos, episiotomia, tricotomia, lavagens e medicações de forma desnecessária, sem consentimento e permissão da mulher; e não permitir que a mulher permaneça com seu filho após o momento do parto (SANTA CATARINA, 2017).

No momento do parto e durante o mesmo a mulher tem por direito e requer atenção, cuidado, empatia, esclarecimentos, participação ativa desses procedimentos e principalmente respeito, assim quando não são estabelecidas o parto e nascimento do bebê pode ser prejudicial representando experiências negativas na vida do binômio (CARVALHO IS e BRITO RS, 2017). 
Outro ponto ressaltado foi o questionamento das gestantes no quesito da falta de recursos hospitalares e profissionais adequados. Em contrapartida, um estudo piloto realizado no Rio de Janeiro mostrou que, a visita guiada na maternidade de referência é de grande importância, devido ao fato de esclarecer dúvidas, como por exemplo, os profissionais atuantes e conhecimento prévio do local onde sucederá o parto, isto influencia diretamente no momento do parto de forma positiva, trazendo tranquilidade e segurança (ALFREDO YM, et al., 2018).

Por fim pode-se dizer que o pré-natal deve ser realizado com atenção, empatia e acolhimento. A consulta de enfermagem deve ser realizada de forma a ter uma escuta qualificada, criando vínculo e exercendo papel educativo, assim a consulta de pré-natal deve ser realizada de forma intercalada entre médico e enfermeiro, para melhor assistência desta gestante (BRASIL, 2012).

Em um estudo na maternidade de um hospital ao norte do Paraná, traz evidências de relatos de gestantes, que enaltecem consultas realizadas por enfermeiros tendo como melhor esclarecimento de dúvidas e riqueza de detalhes no pré-natal (MEDEIROS FF, et al., 2020).

Outra questão importante foi em relação à violência obstétrica sofrida pelas mulheres, onde desde o momento do pré-natal a mulher já relata ter medo dessas situações acontecerem. A violência tratada neste estudo abordou também o fato da omissão de informações da equipe de saúde e de condutas médicas realizadas sem seu consentimento ou sem breve explicação, serem frequentes e acabar invalidando a possibilidade de a gestante tomar suas decisões e expor sua opinião sobre o momento da sua parturição, 0 que gerou dúvidas e insatisfação por parte dessas mulheres.

Esta pesquisa leva a reflexão do quão importante é abordar o tema da violência obstétrica para que mulheres parem de passar por esse sofrimento desnecessário, e que por maiores que sejam as outras possíveis dificuldades naturais do parto, a violência obstétrica não se torne uma opção, ou seja, que não seja algo corriqueiro e nem opcional.

Recomenda-se também que instituições de serviços de saúde fiscalizem e abordem estes temas, incentivando o parto humanizado e a maior empatia neste momento que deve ser único e emocionante na vida de uma mulher, que enfim, terá o papel mais importante: o de ser mãe.

Como limitação do estudo destaca-se sua realização com um grupo de mulheres no período da pesquisa, - que limita a análise da assistência ao parto, considerando que há realidades distintas de outras maternidades, entretanto os resultados são significativos para a assistência ao parto.

O estudo também abre espaço para outras modalidades de pesquisas nessa área relacionada aos medos das gestantes com enfoque nas multigestas e assim observar se medos serão melhores desvelados devido às multíparas já terem passado pela experiência do parto.

\section{CONSIDERAÇÕES FINAIS}

O estudo revelou que gestantes no pré-natal apontam muitos medos relacionados às suas inseguranças, ao medo do desconhecido, medos relacionados aos profissionais se serão devidamente preparados, medos que obtiveram devido a experiências alheias e medo de violência obstétrica. Alguns dos medos como insegurança, achar que seria uma coisa e ser outra, foram desmistificados após elas passarem pelo momento do parto e perceber que não precisavam ter expressado esses sentimentos, porém o medo das dores e medo de violência obstétrica infelizmente não foram desmistificados acontecendo o pior imaginado por elas. Após realizado a análise da pesquisa é notória a falta da consulta de pré-natal realizada pelo profissional enfermeiro, o qual está preparado para realizar uma escuta aprofundada dessa gestante, sendo identificados e logo desvelar alguns medos antes mesmo do parto, podendo minimizar os medos de insegurança e ansiedade desta mulher. 


\section{REFERÊNCIAS}

1. ALFREDO YM, et al. A satisfação com a visita programada à maternidade de referência e sua relação com o momento do parto: um estudo piloto. Revista Aproximando, 2018; 3(4): 1-9

2. BARDIN L. Análise de Conteúdo. São Paulo: 3ำ reimp. 1ำed. 2016; 281 p.

3. BRASIL. Ministério da Saúde. Atenção ao pré-natal de baixo risco / Secretaria de Atenção à Saúde. Departamento de Atenção Básica. - Brasília: Editora do Ministério da Saúde, 2012; 318p. Série A. Normas e Manuais Técnicos. Cadernos de Atenção Básica, (32).

4. BRASIL. Ministério da Saúde. Diretrizes nacionais de assistência ao parto normal: versão resumida / Secretaria de Ciência, Tecnologia e Insumos Estratégicos, Departamento de Gestão e Incorporação de Tecnologias em Saúde. Brasília: 2017; 51p.

5. BRASIL. Ministério da Saúde. Humanização do parto e do nascimento / Universidade Estadual do Ceará. - Brasília: 2014; 4:465p. Cadernos HumanizaSUS.

6. CARVALHO IS, BRITO RS. Formas de violência obstétrica vivenciadas por puérperas que tiveram parto normal. Enfermería Global, 2017; (47): 80-88.

7. DOWNE S, et al. Routine vaginal examinations for assessing progress of labour to improve outcomes for women and babies at term. Cochrane Database Of Systematic Reviews, 2013; (7): 1-37.

8. FREGONESE AA. Gestantes de alto risco com e sem histórico de óbito fetal ou neonatal: sintomas de ansiedade e depressão, capacidade para o relacionamento com o feto e estratégias de enfrentamento, SP. Tese (Doutorado em Ciências da Saúde) - Faculdade de Ciências Médicas da Santa Casa de São Paulo, São Paulo, 2014.

9. KOTTWITZ F, et al. Via de parto preferida por puérperas e suas motivações. Escola Anna Nery, 2017: 22(1): 1-17.

10. LONDRINA. Prefeitura do Município. Secretaria Municipal de Saúde Manual do cuidado no pré-natal e puerpério na atenção primária em Saúde. 2016.

11. MEDEIROS FF, et al. Expectativa e satisfação do acompanhamento pré-natal em gestantes de alto risco. Revista Eletrônica Acervo Saúde, 2020; (40): 1-8.

12. NUNES GS, et al. Sentimentos vivenciados por primigestas. Revista de Enfermagem UFPE OnLine, 2018; 12(4): 916 922.

13. REIS TLR, et al. Autonomia feminina no processo de parto e nascimento: revisão integrativa da literatura. Revista Gaúcha de Enfermagem, 2017; 38(1): 1-8.

14. SANTOS ACC. O reconhecimento da vulnerabilidade da gestante em casos de violência obstétrica. Trabalho Científico (Anais) - Universidade Estadual de Maringá, 2019.

15. SANTA CATARINA. LEI № 17.097, DE 17 DE JANEIRO DE 2017. Dispõe sobre a implantação de medidas de informação e proteção à gestante e parturiente contra a violência obstétrica no Estado de Santa Catarina. Florianópolis, 2017.

16. TOSTES NA, SEIDL EMF. Expectativas de gestantes sobre o parto e suas percepções acerca da preparação para o parto. Temas em Psicologia, 2016; 24(2): 681-693.

17. VALADAO CL, PEGORARO RF. Vivências de mulheres sobre o parto. Fractal Rev sicol, 2020; 32(1):91-8.

18. WESCHENFELDER DT, et al. O enfermeiro na assistência do pré-natal de primigestas: a realidade de uma estratégia de saúde da família. Revista Enfermagem Contemporânea, 2019; 8(1): 7-16.

19. ZANATTA E, et al. A experiência da maternidade pela primeira vez: as mudanças vivenciadas no tornar-se mãe. PesquiPrát Psicossociais, 2017; 12(3):1-16.

20. ZORZAM B, CAVALCANTI P. Direitos das mulheres no parto: conversando com profissionais de saúde e do direito. Coletivo Feminista Sexualidade e Saúde, 1ำed 2017. 